\title{
Short-term enzalutamide treatment for the potential remission of active surveillance or intermediate-risk prostate cancer: a case study, review, and the need for a clinical trial
}

\author{
This article was published in the following Dove Press journal: \\ Research and Reports in Urology \\ 16 July 2014 \\ Number of times this article has been viewed
}

\author{
Mark A Moyad' \\ Mark C Scholz ${ }^{2}$ \\ 'Department of Urology, Jenkins/ \\ Pokempner Preventive and \\ Complementary Medicine, \\ University of Michigan Hospitals \\ and Health Centers, Ann Arbor, \\ MI, USA; ${ }^{2}$ roostate Oncology \\ Specialists, Marina del Rey, \\ CA, USA
}

\begin{abstract}
Active surveillance (AS) is a widely recognized and utilized option by which prostate cancer patients with less aggressive tumors on diagnosis defer immediate traditional conventional therapy (surgery, radiation) and undergo close monitoring by a physician for any clinical or pathologic changes. The juxtaposition of low- to intermediate-risk elderly patients between effective and conventional treatment with associated risks and monitoring without the opportunity for relief of anxiety and other psychological problems can be significant. Minimal and safe treatment over 6 months with the hope of eliminating the existing disease is of significant interest to prostate cancer patients. Unfortunately, dietary supplements have failed to improve and have sometimes even contributed to disease progression. In addition, the use of multiple medications is not always appropriate or safe. In this case study, we administered low doses of enzalutamide ( $80 \mathrm{mg} /$ day $-120 \mathrm{mg} /$ day) in an AS patient during a 6 month period. Results showed a significant reduction in tumor size, as evidenced by magnetic resonance imaging and color Doppler, as well as a an undetectable level of prostate specific antigen during, and immediately following treatment. The use of an oral second-generation androgen-receptor signaling inhibitor was shown to be of benefit to patients unwilling to pursue AS and conventional treatment Administration of enzalutamide did not reduce testosterone levels, but helped maintain good quality of life, was more cost effective at low doses, and was previously shown to be heart healthy and efficacious during early stages of castration-resistant prostate cancer. Although we do not advocate enzalutamide as a treatment approach in these situations, we believe that a clinical trial to evaluate short-term low-dose treatment using enzalutamide is warranted.
\end{abstract}

Keywords: enzalutamide, prostate cancer, active surveillance, dietary supplements, $5 \alpha$-reductase inhibitors

\section{Introduction}

Prostate cancer patients opting for active surveillance (AS) and elderly/comorbid patients with intermediate disease with no hope of temporary, short-term efficacious treatment with minimal toxicity face several issues. Anxiety due to lack of access to treatment is a consistent cause of treatment withdrawal among these patients, and can negatively impact quality of life. ${ }^{1-3}$ These psychological issues can become quite prominent over many years, compared to men treated for prostate cancer. ${ }^{4}$ Surgery, radiation, and off-label use of conventional therapy such as luteinizing hormone-releasing hormone (LHRH) are viable options, but not always realistic or practical. Questions remain regarding their use in terms of benefits versus (vs) risk and long-term costs. ${ }^{5,6}$
Correspondence: Mark A Moyad Department of Urology, Jenkins/ Pokempner Preventive and Complementary Medicine, University of Michigan Hospitals and Health Centers, I 500 East Medical Center Drive, Ann Arbor, MI 48I09, USA

Emailmoyad@umich.edu 
One solution, aside from greater acceptance of AS, is a safe treatment approach with minimal intervention that would be acceptable to prostate cancer patients in a chemoprevention or AS study. A safe and effective chemoprevention option theoretically could be a possibility for AS and vice versa. However, despite perceptions, few novel agents that fit clinical and patient criteria for safety and efficacy are currently being evaluated in clinical trials or proposed as realistic and practical stand-alone options. ${ }^{7}$

Enzalutamide (formerly MDV3100) is a post-docetaxel second-generation androgen-receptor signaling inhibitor approved by the US Food and Drug Administration (FDA) for the treatment of metastatic castrate-resistant prostate cancer (mCRPC) based on results of the Phase III AFFIRM trial. ${ }^{8,9}$ The observation period of enzalutamide was more than twice that of the placebo arm; however, adverse event rates were similar. The enzalutamide arm had a lower incidence of Grade 3 adverse events compared to placebo. Recent studies have shown similar results such as the Phase III PREVAIL trial. These promising results should broaden clinical indications for use of enzalutamide in castrate-resistant prostate cancer (CRPC) settings and increase interest in prostate cancer treatment options. ${ }^{10}$

Results of a Phase II trial evaluating the potential role of enzalutamide monotherapy in 67 hormone-naïve prostate cancer patients were reported at the ASCO 2013 annual meeting. ${ }^{11,12}$ Approximately 39\% of patients had metastatic disease, $36 \%$ had a previous prostatectomy, and $24 \%$ had treatment by radiation. Administration of enzalutamide resulted in a median prostate-specific antigen (PSA) response rate of $93 \%$ and a $99.6 \%$ reduction in PSA levels. Additionally, there were no changes in bone mineral density and metabolic parameters, including lipids, glycemic variables, and body fat index. A recent clinical trial (NCT01547299) examined enzalutamide as a neoadjuvant therapy for patients undergoing radical prostatectomy for localized prostate cancer. ${ }^{9}$ The primary result of the study was a complete response rate that found it to be safe and effective. These results could further strengthen the case for administration of short-term enzalutamide in AS patients.

\section{Case report}

A 77-year-old healthy male patient with a history of trigeminal neuralgia, hypertension, and baseline PSA of $2.7 \mathrm{ng} / \mathrm{mL}$ experienced significant increases in PSA of $3.9 \mathrm{ng} / \mathrm{mL}$ and $4.5 \mathrm{ng} / \mathrm{mL}$ over an 8 month period. Despite a negative 12-core biopsy, his PSA increased to $5.1 \mathrm{ng} / \mathrm{mL}$ within 12 months of his previous PSA and magnetic resonance imaging (MRI) detected a $1 \mathrm{~cm}$ lesion in the left anterior apex. A subsequent biopsy revealed a $3+4=7(10 \%$ Gleason score $)$ and a $3+3=6$ (50\% Gleason score) from the left lateral midgland, as well

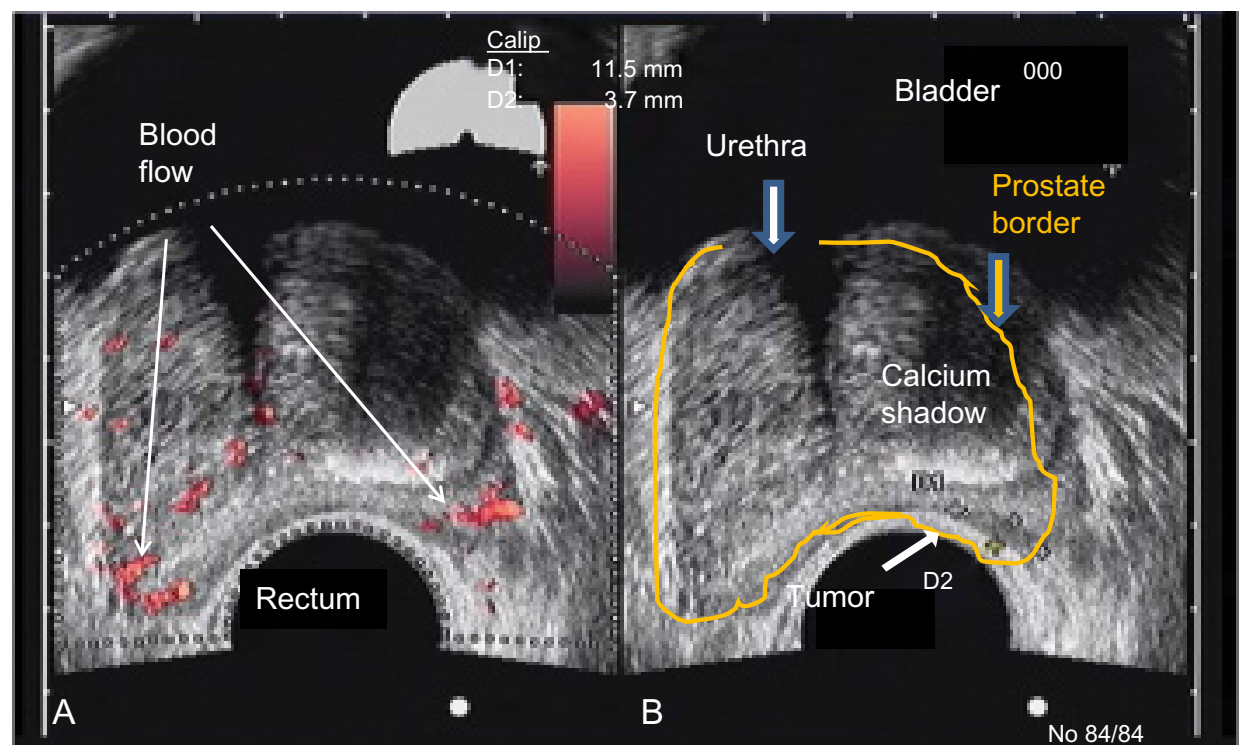

Figure I Color Doppler images of a midgland level cross-section at presentation.

Notes: Image (A) shows an overlay of blood flow (red areas), and image (B) $11.5 \mathrm{~mm} \times 3.7 \mathrm{~mm}$ hypoechoic lesion on the right side of the image (left side of patient demarcated by plus signs).

Abbreviation: $\mathrm{D}$, diameter of the tumor. 
as a $3+3=6(15 \%$ Gleason score $)$ from the right lateral base according to color Doppler. Findings revealed a $48 \mathrm{cc}$ prostate with a distinct hypoechoic lesion in the left midgland extending toward the apex measuring $11 \times 3 \times 14 \mathrm{~mm}$ (Figure 1 ). The patient was reluctant to receive local therapy or AS. He was administered enzalutamide $80 \mathrm{mg}$ /day for 2 weeks, which was then increased to $120 \mathrm{mg} /$ day. He reported mild hot flashes with minimal insomnia and significant reduction in libido. He also reported no breast tenderness but was placed on prophylactic letrozole $2.5 \mathrm{mg}$ every other day. PSA was $1.2 \mathrm{ng} / \mathrm{mL}$ after 2 months on enzalutamide. At 6 months, PSA was undetectable $(<0.1 \mathrm{ng} / \mathrm{mL})$. Color Doppler ultrasound and MRI showed almost complete resolution of the prostate lesion (Figure 2 ). The patient stopped taking enzalutamide and letrozole after 6 months and continued to be monitored. His PSA after 6 months without enzalutamide was $1.9 \mathrm{ng} / \mathrm{mL}$, total testosterone was $430 \mathrm{ng} / \mathrm{dL}$, and color Doppler remained the same as during treatment; he experienced substantial resolution of the lesion. The patient reported minimal or no fatigue and no gynecomastia was noted at the latest physical examination. The patient reported less anxiety and fewer concerns about prostate cancer and continues to be monitored every 4-6 months.

\section{Discussion}

Past and current interventional agents for mCRPC need to be reviewed. This could provide significant impetus for testing of more novel, safe, and effective agents for patients and clinicians concerned about prostate cancer in the minimal to moderate localized disease settings. Safety and efficacy issues have been the focus of previous and current chemoprevention studies; the same concerns exist for potential interventions for prostate cancer AS patients. ${ }^{13}$ For example, initiation and final results of the selenium and vitamin $E$ cancer prevention trial (SELECT) involved numerous factors. ${ }^{14,15}$ These agents failed to prevent prostate cancer, and there were numerous safety and other issues that questioned the relevance of future studies of these nutritional supplement agents.

Selenium has a history of potentially increasing the risk of skin cancer recurrence. ${ }^{16}$ There have also been concerns over increased risk of type 2 diabetes. ${ }^{17}$ Interestingly, the SELECT study found a non-significant increased risk of type 2 diabetes at trial end. ${ }^{14}$ Participants at baseline before the intervention was initiated had serum selenium levels in excess of what was found in previous selenium trials. ${ }^{18,19}$ That is to say, the addition of selenium to over-the-counter dietary supplements such as protein bars, multivitamins, and other snacks during the late 1990s was a potential source of this increase in the American male population deficient in selenium, and converted many men into selenium-replete individuals before the SELECT trial was initiated. ${ }^{7}$ That clinical trial was destined to be unsuccessful because the original hypothesis of nutrient deficiency could not be tested in such

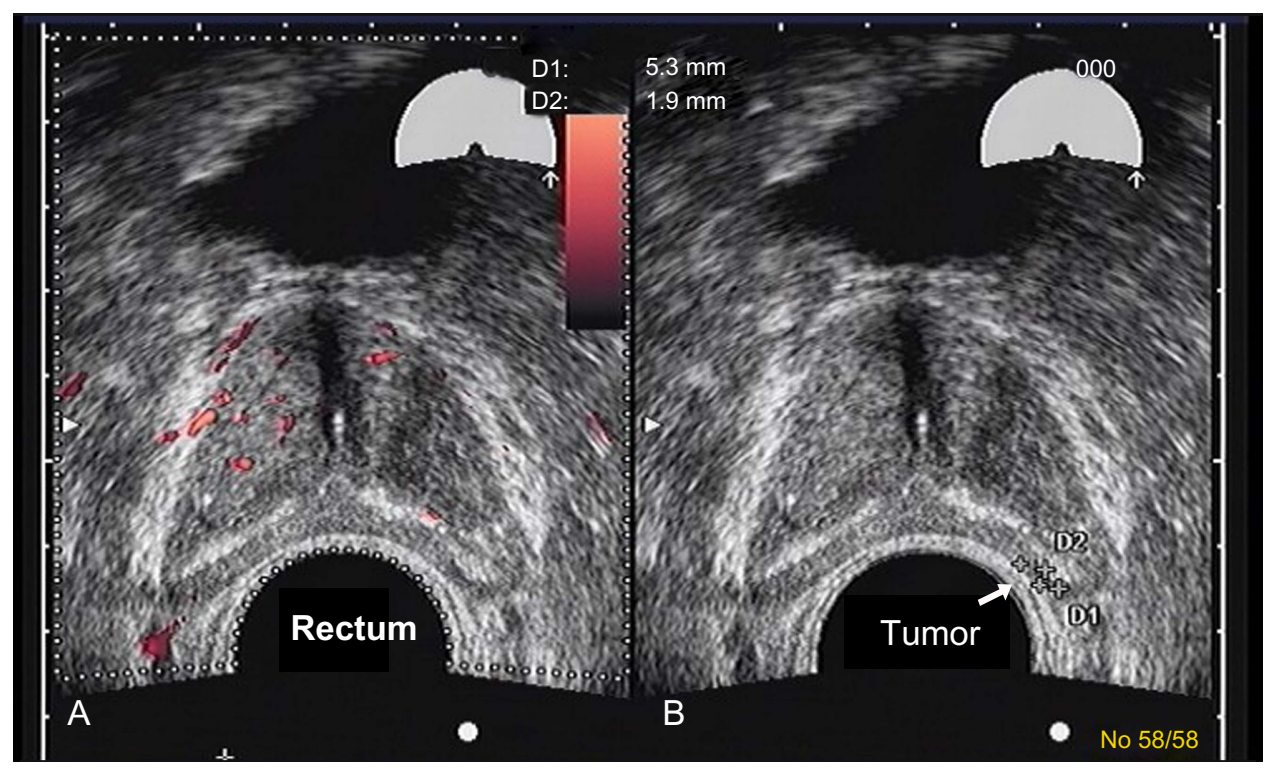

Figure 2 Color Doppler images of a midgland level cross-section after 6 months of treatment.

Notes: (A) Modest blood flow to this area was absent after 6 months of enzalutamide treatment. (B) After 6 months of enzalutamide, the lesion significantly decreased to $5.3 \mathrm{~mm} \times 1.9 \mathrm{~mm}$. Plus signs represent the tumor borders or space occupied by the tumor, which are substantially smaller after drug treatment.

Abbreviation: D, diameter of the tumor. 
a commercially-influenced over-the-counter environment. Interestingly, a Phase II randomized double-blind trial of high-dose (800 $\mu \mathrm{g}$ /day) selenium in AS patients found a significant increase in PSA compared to placebo in men with higher baseline plasma selenium concentrations. ${ }^{20}$

Nutritional supplementation in the US is a $20+$ billion dollar annual industry ${ }^{21}$ that influences exposure to a variety of publicized nutrients. Thus, by the time a nutritional intervention can be tested in a specific nutrient-deficient population, the window of potential empirical evidence has usually passed. A deficiency becomes a situation of excess in part because these nutrients are being added to the diet at the precise moment that they garner some form of minimal media and/or scientific attention. Vitamin C follows this same route; it is worth mentioning that the largest chemoprevention trial of this supplement demonstrated that it had no impact on prostate cancer. ${ }^{22}$

Vitamin D clinical trials are currently under way and levels of vitamin D in the blood could be adequate for most American patients based on the most thoroughly reviewed independent panel report on this supplement; however, the potential risks could be $\geq$ than the benefits. ${ }^{23-25}$ Vitamin $\mathrm{E}$ supplements were also fraught with similar but more significant issues compared to selenium before the SELECT trial. Previous meta-analyses of clinical trials found a potential increase in risk of all-cause mortality with higher doses of vitamin E supplements. ${ }^{26}$ It is also interesting that a significant increased risk of hemorrhagic stroke was found for vitamin E supplement users in another major prostate cancer chemoprevention trial of healthy physicians (the Physicians' Health Study II) that was concurrently conducted during the SELECT study. ${ }^{27}$ In addition, the SELECT study found a nonsignificant $(P=0.06)$ increased risk of prostate cancer in the vitamin $\mathrm{E}$ arm when the study was terminated. ${ }^{14}$ However, on follow-up, the risk of prostate cancer became significant and all intervention arms experienced a non-significant higher risk of aggressive disease risk (Gleason scale $=7+$ ) during the latest follow-up period. ${ }^{15}$ These many controversial issues regarding popular dietary supplements such as chemoprevention agents have been discouraging and should lead to research of more novel methods that could potentially prevent and/or treat minimal disease prostate cancer.

Questions surround the prescription of agents for chemoprevention and/or treatment of minimal disease. Current treatment modalities for breast cancer should be the paradigm for concerns regarding reproductive hormone-derived and proliferating cancer to be eradicated in minimal disease and highrisk prevention settings due to significant clinical treatment similarities between these two carcinomas. ${ }^{28}$ For example, the drug tamoxifen was used and the FDA approved both scenarios (chemoprevention and treatment); as a result, tamoxifen is currently being used in patients with more extensive disease. ${ }^{29}$ This has also led to an ongoing interest in aromatase inhibitors for use in similar clinical scenarios. However, use of tamoxifen is hindered by long-term use constraints and significant safety issues in minimal or absence of disease. This is the primary reason why healthy women have not embraced this and other agents because of acute and chronic toxicities. ${ }^{30}$ An increased risk of uterine cancer, accelerated menopausal issues, and an increase in cardiovascular disease and cataracts appeared to outweigh the benefits of tamoxifen in many patients except in more advanced disease. ${ }^{30,31}$

Raloxifene, a selective estrogen receptor modulator can have dual treatment effects in bone loss prevention and breast cancer. A Phase III comparison trial showed raloxifene to be as effective as tamoxifen and relatively safer due to the absence of increased risk of uterine cancer. However, increased risk of blood clots, stroke, and non-invasive disease were not synonymous with advances in chemoprevention but lateral and minimal steps forward. ${ }^{31,32}$ Treatment with aromatase inhibitors could be an option for this patient population but could be limited by similar issues when tested in minimal-disease patients.

Using breast cancer as a paradigm, it becomes easier to interpret most controversies surrounding similar agents for prostate cancer prevention and minimal to moderate localized disease treatments. Finasteride has been found to prevent non-aggressive prostate cancer, but with the side-effect of impacting sexual and reproductive function and the potential, albeit highly controversial, of enhanced risk of being diagnosed with aggressive prostate and breast cancer. ${ }^{33,34}$ The use of dutasteride engenders similar concerns as finasteride. ${ }^{35,36}$ The FDA rejected the ability of these agents to be commercialized for prostate cancer prevention, and arguably, minimal disease-treatment drugs even though they did prevent some forms of prostate cancer. ${ }^{37,38}$ However, safety issues as opposed to efficacy appear to be responsible for the FDA's rejection notice. For example, decrease in sexual function, mental health, quality of life, and other issues remain important concerns. ${ }^{39}$

More importantly, what needs to be acknowledged from studies on finasteride and dutasteride, similarly to observations in breast cancer, is that an agent that prevents high-risk prostate cancer can also be effective in minimal- and low-risk treatment situations, and possibly in advanced disease. ${ }^{40}$ This should provide impetus for ongoing research and use of safer, 
more effective agents that do not engender compliance issues over long periods. The use of 5-alpha-reductase inhibitors in AS exists $;{ }^{41}$ however, concerns about clinical and pathologic efficacy vs risks remains controversial and requires further elucidation. ${ }^{42,43}$ For example, the Reduction by Dutasteride of Clinical Progression Events in Expectant Management (REDEEM) trial examining daily dutasteride in low-risk T1cT2 a prostate cancer patients showed a $38 \%$ compared to $48 \%$ progression in the placebo arm after 3 years. ${ }^{44}$ Dutasteride significantly delayed prostate cancer progression by $38 \%$ $(P=0.009)$.

However, unlike the patient in the current case study, patients in the REDEEM trial required a Gleason score of 4 to 6 . REDEEM results were not without critics who disputed the results of 3 years vs 18 months in terms of pathological progression that showed no differences between the groups. They also mentioned that not correcting for PSA changes was tantamount to patients not interpreting the risk to benefit ratios. ${ }^{43}$ Nevertheless, results showed that dutasteride had different mechanisms of action than enzalutamide. As such, future clinical studies on combining these agents could potentially determine whether synergism between the two agents actually exists.

Studies over the past decade have shown that LHRH can result in control or remission of localized prostate cancer. ${ }^{45}$ A retrospective study supports this finding. ${ }^{46}$ Japanese prostate cancer patients were effectively treated with LHRH therapy, which appeared to be equal to conventional treatment. ${ }^{47,48}$ However, toxicity can occur during this stage, even during short duration. These results provide a serious rationale and ideal scenario for further testing of these products in a minimal disease setting. ${ }^{49,50}$ Abiraterone is no different in terms of benefit-to-risk scenarios in the AS population because of similar castration effects and additional requirements for concomitant steroid utilization and potential for increased cardiovascular and blood pressure complications. ${ }^{51}$

Bicalutamide treatment is another option, however it has been shown to have a higher mortality rate in men with early-stage disease, and the increased androgen receptor signaling inhibition, and a positive safety record of treating CRPC with enzalutamide, thus makes it the anti-androgen drug of choice. ${ }^{8,10-12,52}$ The potential of using statin drugs for testing men with minimal disease is interesting. ${ }^{7}$ However, recent concerns over a high risk of developing type 2 diabetes has resulted in a situation of some controversy especially for intensive or high-dose statin treatment. ${ }^{53}$ Our 2011 study, conducted a clinical trial of red yeast rice dietary supplements (statin mimic) for patients with AS in Toronto, ON, Canada; we look forward to reporting future results. ${ }^{54}$

Administration of metformin is an interesting alternative, but additional data are required to determine its role in AS. The addition of a statin and/or metformin to a potentially effective AS agent is also of interest. ${ }^{7}$ Dietary and lifestyle therapies for AS have been examined in a preliminary study; ${ }^{55}$ results could be added to current treatment options. However, we believe that it would be difficult to incorporate these results for use as generalized stand-alone options due to compliance issues and little known efficacy in eradicating existing diseases.

Enzalutamide has the potential to meet most, or all criteria for use as a minimal treatment option for AS patients, as well as some intermediate-risk patients due to its combination of safety and efficacy as shown in clinical trials. ${ }^{8,10-12}$ The fact that a potentially safe oral therapy for CRPC or any cancer is available for the first time suggests that it could have additional applications in the early disease processes of hormonal naïve prostate cancer. Enzalutamide does not require steroid use or dietary restrictions. Study results on the safety of MDV3100 showed fatigue in a small number of patients, which was quickly reversed by discontinuation of therapy. ${ }^{56}$ However, based on our case study results, we believe that $50 \%-75 \%$ of the standard dose ( $80 \mathrm{mg} /$ day- $120 \mathrm{mg}$ /day) could be used over a 6 month period, with the advantages of affordability, minimal fatigue, and stable testosterone levels. Concerns about gynecomastia can be alleviated by prophylactic use of an antiestrogens such as letrozole. There is minimal risk of seizures, which could be further minimized by not treating high- or at-risk seizure patients, for example those using medications that could lower seizure threshold. In addition, the risk of cardiovascular disease (CVD) with enzalutamide has been shown to be similar to placebo, thereby making it very attractive as a minimal treatment option since CVD is the primary cause of mortality in men and those using AS. ${ }^{7}$ Nevertheless, it should be reiterated that the purpose of the current case study was to stimulate debate, and encourage further research. The authors in no way advocate the described treatment modality for use in intermediate-risk AS patients. We respect the desire of a small number of patients to try a novel and costly therapy despite not being fully aware of the true risk-to-benefit scenario in this specific setting.

Studies on neoadjuvant therapy are necessary; however, the main concern about enzalutamide is a lack of clinical data on its effects on hormone naïve prostate tissue over short and long terms. Such data will provide additional knowledge about tissue, serum, imaging, and safety/ 
quality of life. A preliminary clinical trial would provide new information about treatment of localized disease and contribute to new applications such as monotherapy, combination therapy, and cocktails that simultaneously exploit various tumor characteristics. Another potential result could be new insights for researchers to consider. For example, prostate cancer patients could benefit from oral-based interventions that could potentially eliminate this disease or place it in remission long enough for competing causes of mortality to become more of an issue long-term. This may sound dramatic, but it is our opinion that any knowledge generated from such a preliminary study would represent a significant, symbolic, and realistic advance towards minimizing one of the leading causes of mortality from cancer in men.

\section{Disclosure}

This case report and review article was written and reviewed without any funding. Dr Moyad allows his consumer educational books to be purchased by pharmaceutical companies including Astellas and Medivation. Dr Scholz has completed paid clinical research for Medivation and received remuneration for speaking on behalf of the company. The authors report no other conflicts of interest in this work.

\section{References}

1. Dale W, Bilir P, Han M, Meltzer D. The role of anxiety in prostate carcinoma: a structured review of the literature. Cancer. 2005;104(3): 467-478.

2. Latini DM, Hart SL, Knight SJ, et al for the CaPSURE Investigators. The relationship between anxiety and time to treatment for patients with prostate cancer on surveillance. J Urol. 2007;178(3 Pt 1):826-831.

3. Ercole B, Marietti SR, Fine J, Albertsen PC. Outcomes following active surveillance of men with localized prostate cancer diagnosed in the prostate specific antigen era. J Urol. 2008;180(4):1336-1339.

4. Bergman J, Litwin MS. Quality of life in men undergoing active surveillance for localized prostate cancer. J Natl Cancer Inst Monogr. 2012;2012(45):242-249.

5. Wilt TJ, MacDonald R, Rutks I, Shamliyan TA, Taylor BC, Kane RL. Systematic review: comparative effectiveness and harms of treatments for clinically localized prostate cancer. Ann Intern Med. 2008;148(6): 435-438.

6. [No authors listed]. Management of localized prostate cancer: watchful waiting, surgery or radiation therapy, depending on the natural course, which is often relatively slow. Prescrire Int. 2012;21(131): 242-248.

7. Moyad MA. Heart healthy = prostate healthy: SELECT, the symbolic end of preventing prostate cancer via heart unhealthy and over anti-oxidation mechanisms? Asian J Androl. 2012;14(2):243-244.

8. Scher HI, Fizazi K, Saad F, et al. Increased survival with enzalutamide in prostate cancer after chemotherapy. $N$ Engl J Med. 2012;367(13): 1187-1197.

9. El-Amm J, Patel N, Freeman A, Aragon-Ching JB. Metastatic castrationresistant prostate cancer: critical review of enzalutamide. Clin Med Insights Oncol. 2013;7:235-245.
10. Medivation and Astellas announce the phase 3 PREVAIL trial of enzalutamide meets both co-primary endpoints of overall survival and radiographic progression-free survival in chemotherapy-naïve patients with advanced prostate cancer. Available at http://www.investors.medivation.com/releasedetail.cfm?ReleaseID=798880. Accessed October 23, 2013.

11. Tombal B, Borre M, Rathenborg P, et al. Enzalutamide monotherapy: Phase II study results in patients with hormone-naive prostate cancer. J Clin Oncol. 2013;31(Suppl 6): Abstr 18.

12. Smith MR, Borre M, Rathenborg P, et al. Efficacy and safety of enzalutamide (ENZA) monotherapy in hormone-naive prostate cancer (HNPC). J Clin Oncol. 2013;31(Suppl): Abstr 5001.

13. Moyad MA. Selenium and vitamin E supplements for prostate cancer: evidence or embellishment? Urology. 2002;59(4 Suppl 1): 9-19.

14. Lippman SM, Klein EA, Goodman PJ, et al. Effect of selenium and vitamin $E$ on risk of prostate cancer and other cancers: the Selenium and Vitamin E Cancer Prevention Trial (SELECT). JAMA. 2009;301(1):39-51.

15. Klein EA, Thompson IM Jr, Tangen CM, et al. Vitamin E and the risk of prostate cancer: the Selenium and Vitamin E Cancer Prevention Trial (SELECT). JAMA. 2011;306(14):1549-1556.

16. Duffield-Lillico AJ, Slate EH, Reid ME, et al. Selenium supplementation and secondary prevention of non-melanoma skin cancer in a randomized trial. J Natl Cancer Inst. 2003;95(19):1477-1481.

17. Stranges S, Marshall JR, Natarajan R, et al. Effects of long-term selenium supplementation on the incidence of type 2 diabetes: a randomized trial. Ann Intern Med. 2007;147(4):217-223.

18. Clark LC, Combs GF Jr, Turnbull BW, et al. Effects of selenium supplementation for cancer prevention in patients with carcinoma of the skin. A randomized controlled trial. Nutritional Prevention of Cancer Study Group. JAMA. 1996;276(24):1957-1963.

19. Clark LC, Dalkin B, Krongrad A, et al. Decreased incidence of prostate cancer with selenium supplementation: results of a double-blind cancer prevention trial. Br J Urol. 1998;81(5):730-734.

20. Stratton MS, Algotar AM, Ranger-Moore J, et al. Oral selenium supplementation has no effect on prostate-specific antigen velocity in men undergoing active surveillance for localized prostate cancer. Cancer Prev Res (Phila). 2010;3(8):1035-1043.

21. Nahin RL, Barnes PM, Stussman BJ, Bloom B. Costs of complementary and alternative medicine (CAM) and frequency of visits to CAM practitioners: United States, 2007. Natl Health Stat Report. 2009;18:1-16.

22. Gaziano JM, Glynn RJ, Christen WG, et al. Vitamins E and C in the prevention of prostate and total cancer in men: the Physicians' Health Study II randomized controlled trial. JAMA. 2009;301(1): $52-62$.

23. Slomski A. IOM endorses vitamin D, calcium only for bone health, dispels deficiency claims. JAMA. 2011;305(5):453-453.

24. Ross AC, Manson JE, Abrams SA, et al. The 2011 report on dietary reference intakes for calcium and vitamin D from the Institute of Medicine: what clinicians need to know. J Clin Endocrinol Metab. 2011;96(1):53-58.

25. Dietary reference intakes for calcium and vitamin D. Institute of Medicine (US) Committee to Review Dietary Reference Intakes for Vitamin D and Calcium. The National Academies Press. 2011 Washington, DC, USA.

26. Miller ER 3rd, Pastor-Barriuso R, Dalal D, Riemersma RA, Appel LJ, Guallar E. Meta-analysis: high-dosage vitamin E supplementation may increase all-cause mortality. Ann Intern Med. 2005;142(1): $37-46$.

27. Sesso HD, Buring JE, Christen WG, et al. Vitamins E and C in the prevention of cardiovascular disease in men: the Physicians' Health Study II randomized controlled trial. JAMA. 2008;300(18):2123-2133.

28. Risbridger GP, Davis ID, Birrell SN, Tilley WD. Breast and prostate cancer: more similar than different. Nat Rev Cancer. 2010;10(3): 205-212. 
29. Jordan VC. Tamoxifen: catalyst for the change to targeted therapy. Eur J Cancer. 2008;44(1):30-38.

30. Chlebowski RT, Geller ML. Adherence to endocrine therapy for breast cancer. Oncology. 2006;71(1-2):1-9.

31. Vogel VG. The NSABP Study of Tamoxifen and Raloxifene (STAR) trial. Expert Rev Anticancer Ther. 2009;9(1):51-60.

32. Messalli EM, Scaffa C. Long-term safety and efficacy of raloxifene in the prevention and treatment of postmenopausal osteoporosis: an update. Int $J$ Womens Health. 2010;1:11-20.

33. Thompson IM, Goodman PJ, Tangen CM, et al. The influence of finasteride on the development of prostate cancer. $N$ Engl $J$ Med. 2003;349(3):215-224.

34. McConnell JD, Roehrborn CG, Bautista OM, et al. The long-term effect of doxazosin, finasteride, and combination therapy on the clinical progression of benign prostatic hyperplasia. N Engl J Med. 2003;349(25): 2387-2398.

35. Andriole GL, Bostwick DG, Brawley OW, et al. Effect of dutasteride on the risk of prostate cancer. N Engl J Med. 2010;362(13):1192-1202.

36. Walsh PC. Chemoprevention of prostate cancer. $N$ Engl J Med. 2010;362(13):1237-1238.

37. FDA. Oncologic Drugs Advisory Committee Meeting of the Food and Drug Administration, Center for Drug Evaluation and Research regarding AVODART (dutasteride) sNDA. FDA 21319/S0024. 2010. Available at: http://www.fda.gov/downloads/ AdvisoryCommittees/CommitteesMeetingMaterials/Drugs/ OncologicDrugsAdvisoryCommittee/UCM239355.pdf. Accessed December 30, 2014.

38. FDA. Oncologic Drugs Advisory Committee Meeting regarding PROSCAR (finasteride) NDA 20180/S034. 2010. Available at: http://www.fda.gov.proxy.lib.umich.edu/downloads/ AdvisoryCommittees/CommitteesMeetingMaterials/Drugs/ OncologicDrugs AdvisoryCommitte/UCM234934. Accessed December 30, 2014.

39. Traish AM, Hassani J, Guay AT, Zitzmann M, Hansen ML. Adverse side effects of $5 \alpha$-reductase inhibitors therapy: persistent diminished libido and erectile dysfunction and depression in a subset of patients. $J$ Sex Med. Mar 2011;8(3):872-884.

40. Sartor O, Nakabayashi M, Taplin ME, et al. Activity of dutasteride plus ketoconazole in castration-refractory prostate cancer after progression on ketoconazole alone. Clin Genitourin Cancer. 2009;7(3):E90-E92. Available at http://www.ncbi.nlm.nih.gov/pubmed/?term=Activity+of + dutasteride+plus+ketoconazole+in+castration-refractory+prostate+can cer+after+progression+on+ketoconazole+alone. Accessed February 15, 2014.

41. Chiang AS, Loblaw DA, Jethava V, et al. Utility of 5-alpha-reductase inhibitors in active surveillance for favourable risk prostate cancer. $\mathrm{Can}$ Urol Assoc J. 2013;7(11-12):450-453.

42. Ross AE, Feng Z, Pierorazio PM, et al. Effect of treatment with 5- $\alpha$ reductase inhibitors on progression in monitored men with favourablerisk prostate cancer. BJU Int. 2012;110(5):651-657.
43. Walsh PC. Re: Dutasteride in localized prostate cancer management: the REDEEM randomized, double-blind, placebo-controlled trial. J Urol. 2012;188(1):110-111.

44. Fleshner NE, Lucia MS, Egerdie B, et al. Dutasteride in localized prostate cancer management: the REDEEM randomized, double-blind, placebo-controlled trial. Lancet. 2012;379(9821):1103-1111.

45. Labrie F, Candas B, Gomez JL, Cusan L. Can combined androgen blockade provide long-term control or possible cure of localized prostate cancer? Urology. 2002;60(1):115-119.

46. Scholz MC, Groom MK, Kaddis AJ, et al. Primary androgen deprivation (AD) followed by active surveillance (AS) for newly diagnosed prostate cancer (PC): a retrospective study. Prostate. 2013;73(1):83-88.

47. Ueno S, Namiki M, Fukagai T, Ehara H, Usami M, Akaza H. Efficacy of primary hormonal therapy for patients with localized and locally advanced prostate cancer: a retrospective multicenter study. Int $J$ Urol. 2006;13(12):1494-1500.

48. Kobayashi M, Nukui A, Suzuki K, Kurokawa S, Morita T. Clinical efficacy of primary combined androgen blockade for Japanese men with clinically localized prostate cancer unsuitable for local definitive treatment: a single institution experience. Int J Clin Oncol. 2011;16: 630-636.

49. Collins L, Basaria S. Adverse effects of androgen deprivation therapy in men with prostate cancer: a focus on metabolic and cardiovascular complications. Asian J Androl. 2012;14(2):222-225.

50. Cussenot O, Cornu JN, Drouin SJ, et al. Secondary chemoprevention of localized prostate cancer by short-term androgen deprivation to select indolent tumors suitable for active surveillance: a prospective pilot phase II study. World J Urol. 2013;32(2):545-550.

51. de Bono JS, Logothetis CJ, Molina A, et al. Abiraterone and increased survival in metastatic prostate cancer. $N$ Engl $J$ Med. 2011;364(21):1995-2005.

52. Guerrero J, Alfaro IE, Gomez F, Protter AA, Bernales S. Enzalutamide, an androgen receptor signaling inhibitor, induces tumor regression in a mouse model of castration-resistant prostate cancer. Prostate. 2013;73(12):1291-1305.

53. Preiss D, Sattar N. Statins and the risk of new-onset diabetes: a review of recent evidence. Curr Opin Lipidol. 2011;22(6):460-466.

54. Moyad MA, Klotz LH. Statin clinical trial (REALITY) for prostate cancer: an over 15-year wait is finally over thanks to a dietary supplement. Urol Clin N Am. 2011;38(3):325-331.

55. Frattaroli J, Weidner G, Dnistrian AM, et al. Clinical events in prostate cancer lifestyle trial: results from two years of follow-up. Urology. 2008;72(6):1319-1323.

56. Scher HI, Beer TM, Higano CS, et al. Antitumor activity of MDV3100 in castration-resistant prostate cancer: a phase 1-2 study. Lancet. 2010;375(9724):1437-1446.
Research and Reports in Urology

\section{Publish your work in this journal}

Research and Reports in Urology is an international, peer-reviewed, open access journal publishing original research, reports, editorials, reviews and commentaries on all aspects of adult and pediatric urology in the clinic and laboratory including the following topics: Pathology, pathophysiology of urological disease; Investigation and treatment of

\section{Dovepress}

urological disease; Pharmacology of drugs used for the treatment of urological disease. The manuscript management system is completely online and includes a very quick and fair peer-review system, which is all easy to use. Visit http://www.dovepress.com/testimonials.php to read real quotes from published authors. 